\title{
Erratum to: Adverse Drug Reactions and Impaired Renal Function in Elderly Patients Admitted to the Emergency Department
}

\section{A Retrospective Study}

\author{
Anders Helldén • Ulf Bergman • Mia von Euler • \\ Maria Hentschke • Ingegerd Odar-Cederlöf • \\ Gunnar Öhlén
}

Published online: 7 November 2013

(C) Springer International Publishing Switzerland 2013

Erratum to: Drugs Aging 2009; 26(7):595-606

\section{DOI 10.2165/11315790-000000000-00000}

Pages 601-602: Table 5 contained a number of incorrect values within the columns for compensated plasma creatinine (Comp P-CR) and estimated creatinine clearance $\left(\mathrm{eCL} \mathrm{L}_{\mathrm{CR}}\right)$.

The table should read as follows (corrected values shown in bold):

The online version of the original article can be found under doi:10.2165/11315790-000000000-00000.

A. Helldén $(\varangle) \cdot$ U. Bergman · M. von Euler · M. Hentschke · I. Odar-Cederlöf

Regional Pharmacovigilance Unit, Division of Clinical

Pharmacology, Department of Laboratory Medicine,

Karolinska University Hospital, Huddinge,

Karolinska Institutet, Stockholm, Sweden

e-mail: anders.hellden@karolinska.se

G. Öhlén

Department of Emergency Medicine, Karolinska University

Hospital, Huddinge, Stockholm, Sweden 







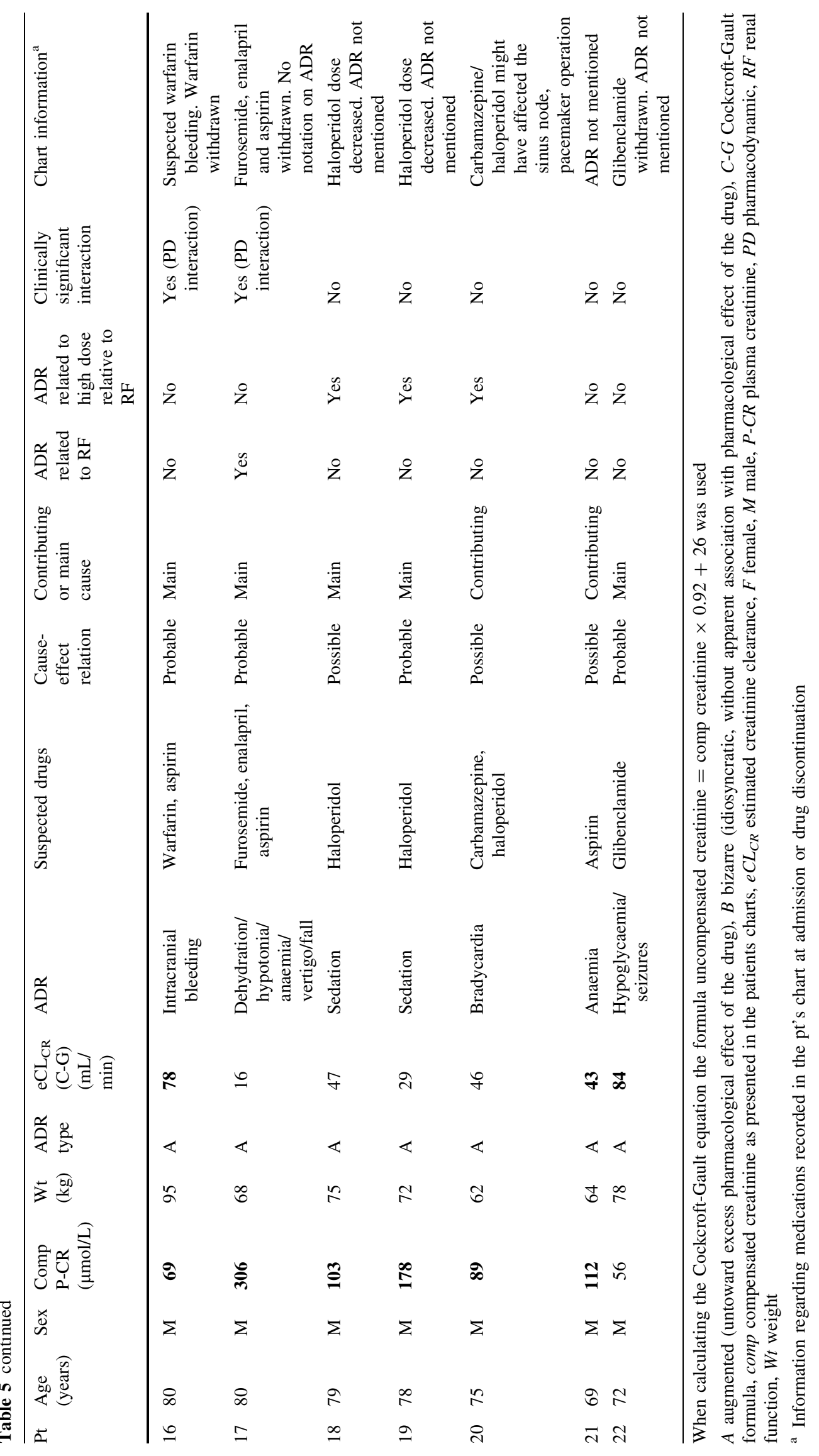

